\title{
EVALUATE THE SORPTION BEHAVIOR AND IDENTIFICATION OF OPTIMUM DRYING CONDITIONS OF Phylanthus ambelica (NELLI) AND Zingiber officinale (GINGER)
}

\author{
R. M. N. A. Wijewardane ${ }^{1}$, C. R. Gunawardane ${ }^{1}$, K. B. Palipane ${ }^{2}$, \\ K. V. T. Gunawardena ${ }^{3}$, H. C. Samarakoon ${ }^{1}$ and M. D. Fernando ${ }^{1}$
}

\begin{abstract}
Drying behavior and the optimum drying conditions of Phylanthus ambelica (Nelli) and Zingiber officinale (Ginger) were evaluated. Moisture sorption isotherms were determined using the static gravimetric method using saturated salt solutions of water activities range from $0.05 \%-0.92 \%$ at two temperatures of $30^{\circ} \mathrm{C}$ and $50^{\circ} \mathrm{C}$. Modified Henderson, Modified Chung-Pfost and GAB models were used to fit the experimental data and it was best fitted by the Chung-Pfost model. Thus Chung-Pfost model was used for the estimation of the equilibrium moisture content of tested medicinal crops. The process conditions for drying were optimized and $50^{\circ} \mathrm{C}$ was found to be the best suitable drying temperature for Phylanthus ambelica (Nelli) as well $40^{\circ} \mathrm{C}$ was preferred for Zingiber officinale (Ginger) with respect to preservation of its volatile substance significantly $(p<0.05)$.
\end{abstract}

Key Words: Phylanthus ambelica, Zingiber officinale, Drying, Adsorption, Desorption

\section{INTRODUCTION}

There are over 655 medicinal plant species used for medicinal purpose in Sri Lanka and about 208 are commonly used in the Ayurved medicine (Jayaweera, 1982). Among those, 80 major plant species are now considered to be threatened in Sri Lanka (Abeywardana and Hettiaratchi, 2001).Medicinal plants have been an important resource for human health care from prehistoric times to the present day. About 35\% of the Sri Lankan population is primarily dependent on Ayurveda and traditional systems of health care, particularly in rural situations (Jayaweera, 1982).

Majority of the rural population in the third world countries still depend on traditional medical treatments at the initial level. Indigenous pharmaceutical industry, as that of the western medicine is being developed gradually. This seems to be inextricably woven with the global trend on natural medicine and alternative medical practices. This has a direct influence on the increased demand in the national market.
The medicinal properties of nelli have been well enumerated in Ayurvedic texts and the importance of this fruit is recognized for health life. The dried fruit of Nelli is used as a raw material in Ayurvedic medicine. Sri Lanka spent about a million rupees to import dried Nelli due to low production and lack of appropriate techniques to dry the fruits. Hence it is prime importance to increase extent of cultivation and develop techniques to dry the fruits up to quality standards. Further it is important to develop value added products (Pushpakumara and Heenkenda, 2007).

Ginger is available in market as fresh ginger or in dry form. Dried ginger is powdered and used for different products. Ginger oils and oleoresins are used in the food industry as a spice to flavor curries, bakery \& other food products and to some extent in the perfumery industry, Also it is a common ingredient in the Ayurvedic medical system till today.

\footnotetext{
I Institute of postharvest Technology, Jayanthi Mawatha, Anuradhapura, Sri Lanka

2 Faculty of Applied Sciences, University of Sabaragamuwa, Belihuloya, Sri Lanka

3 Industrial technology Institute, Baudhaloka Mawatha, Colombo 7, Sri Lanka
} 
Medicinal plants are used widely in Sri Lanka for drug and cosmetic manufacturing practices both by the government and private sector. However, the quantification of the aggregate use of medicinal plants have not yet being carried out. Such estimates will have important implications for the medicinal plant cultivation programmes and recommendation of proper conservation and sustainable use practices (Isuru and Gunawardena, 2008).

Certain countries, from which medicinal raw materials are imported, have imposed limitations on their export and hence it is time to cultivate and process them in local conditions. Many medicinal and aromatic plants are labour intensive in production, harvesting, postharvest processing and packaging. Many medicinal plants are seasonal, inaccessible and can be found only in deep forest or mountain peaks. Such restrictions necessitate finding out ways and devices to store them for future use. Sizable quantitative and qualitative losses still occur in drying and subsequent post harvest handling. The main problem is preservation of colour during drying. Because of inappropriate harvesting practices qualitative and quantitative losses can be seen. After harvesting and processing, it is difficult to store them for more than 2-3 months. Insects and fungal attacks are the prominent during storage and weight loss also can be seen because of poor storage conditions.

Air temperature and water content affect the storage life of agricultural products and increasing these factors causes an increase in product respiration and trends to short storage life (Copeland and MacDonald, 1995). EMC (Equilibrium Moisture Content) is durability criteria and any change in quality of foods and agricultural products during storage is crucially important (Veltchew and Menkew, 2000).Fundamental relationship between EMC and relative humidity of food products is known as sorption isotherms ( Palipane and Driscroll,1992).
The objective of this study was to evaluate the drying behavior and the optimum drying conditions of economically important medicinal crops as $P$. ambelica and $Z$. officinale.

\section{MATERIALS AND METHODS}

\section{Sample preparation}

Freshly harvested Phylanthus ambelica (Nelli) and Zingiber officinale (Ginger) were used in the experiment. Ginger was harvested in the morning time from farmer field at kurunegala (North Western part of Sri Lanka) and transported within 3 hours to the laboratory of Institute of Postharvest Technology. Nelli was collected from home garden at Bibila (Uva province) in the evening time and transported to the laboratory for experimentation.

Fresh samples of Nelli and Ginger were used in desorption experiments. And for adsorption studies, the moisture content of the plant was brought down to as close as to zero percent moisture under vacuum at 0.6 bars. The temperature was regulated at $50^{\circ} \mathrm{C}$ and the samples were dried until reaching moisture content less than 4\% (AOAC, 1990).

From each sample of Nelli and ginger about $20 \mathrm{~g}$ were taken and initial moisture content was determined by the Dean and Stark method (AOAC, 1990) as the samples contain significant amount of volatiles. Sorption isotherms at $30^{\circ} \mathrm{C}$ and $50^{\circ} \mathrm{C}$ were determined through the static gravimetric method (Bell and Labuza, 2000) using nine saturated salt solutions $\left(\mathrm{KOH}, \mathrm{CH}_{3} \mathrm{COOH}, \mathrm{K}_{2} \mathrm{CO}_{3}, \mathrm{NaBr}\right.$, $\mathrm{NaCl}, \mathrm{KNO}_{3}$, and $\mathrm{KCl}$ ) with water activity ranged from $0.06-0.92$ (Table 01).

To plot the moisture sorption isotherms for the product, Equilibrium Moisture Contents (EMC) were determined at seven relative humidity conditions ranged from $0.05-0.92$ $\mathrm{a}_{\mathrm{w}} \cdot 30^{\circ} \mathrm{C}$ and $50^{\circ} \mathrm{C}$ were determined as the drying temperature to develop isotherms. 
Table 01: Greenspan values for saturated salts used by FDA(Food and DrugAdministration)

\begin{tabular}{lcc}
\hline \multirow{1}{*}{ Name of chemical } & Water activity $\left(\mathbf{a}_{\mathbf{w}}\right)$ \\
\cline { 2 - 3 } & $\mathbf{3 0}^{\circ} \mathbf{C}$ & $\mathbf{5 0}^{\circ} \mathbf{C}$ \\
\hline $\mathrm{KOH}$ & 0.07 & 0.06 \\
$\mathrm{CH}$ & 0.21 & 0.19 \\
$\mathrm{~K}_{2} \mathrm{COOH}$ & 0.43 & 0.42 \\
$\mathrm{NaBr}$ & 0.56 & 0.51 \\
$\mathrm{NaCl}$ & 0.75 & 0.74 \\
$\mathrm{KCl}$ & 0.83 & 0.81 \\
$\mathrm{KNO}_{3}$ & 0.92 & 0.84 \\
\hline
\end{tabular}

(Source: Bell \& Labuza, 2000)

Air tight small glass jars with $9 \mathrm{~cm}$ diameter and $16 \mathrm{~cm}$ height were used with saturated salt solutions. Saturated salt solutions were prepared by adding distilled water slowly into the salt crystals with constant stirring until about half of the salt crystals were dissolved. Glass stands were used to hold the sample above the salt solutions. The sample containing jars were placed in incubators until they reach equilibrium moisture content, under temperature of $30^{\circ} \mathrm{C}$ and $50^{\circ} \mathrm{C}$. Dean and Stark method was used to determine the equilibrium moisture content (wet basis). Averages EMC value of two replicates under each $\mathrm{a}_{\mathrm{w}}$ and fixed temperature were obtained.

After data collection, dry basis moisture content was plotted against $\mathrm{a}_{\mathrm{w}}$. Modified Henderson, Modified Chung-Pfost, and GAB equations were selected for analyzing the best fit model.

a. Modified Henderson Equation

$$
M C d b=\left[\frac{\operatorname{In}(1-\mathrm{a} W)}{-A(T+\mathrm{C})}\right]^{1 / B}
$$

b. Modified Chung-Pfost equation

$$
M C d b=\operatorname{In}\left[\frac{\operatorname{In} \mathrm{a} W(\mathrm{~T}+\mathrm{C})}{-A}\right] \frac{1}{-B}
$$

c. Guggenheim-Anderson-deBoer (GAB) equation

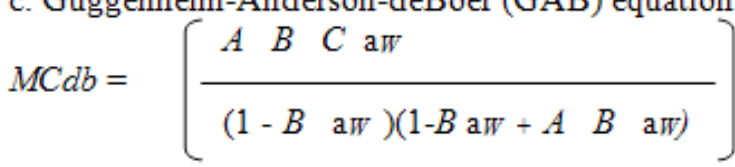

Where;

$\mathrm{a}_{W} \quad$ Water activity as decimal

$M C d b \quad$ dry basis equilibrium moisture content

$A, B, C \quad$ model parameters

\section{Testing optimum drying temperature}

Primary test was conducted to determine the optimum temperature for drying based on the loss of volatile compounds at different drying temperatures at 40 and $50{ }^{\circ} \mathrm{C}$. Total moisture, water soluble extracts and alcohol soluble extracts of Nelli and ginger were determined (AOAC, 1990).

The product after drying under each method was divided into two and one sample was subjected to test remaining moisture by the Dean and stark method and the other was oven dried at $105^{\circ} \mathrm{C}$ to determine the remaining moisture and volatiles. Finally a volatile loss during drying was determined using following equation.

MVL $=$ TMV-RMV

$\mathrm{ML}=\mathrm{IM}-\mathrm{RM}$

$\mathrm{VL}=$ MVL-ML

Where,

MVL = Moisture and volatile loss during drying at any given condition. 
$\mathrm{TMV}=$ Total initial moisture and volatile content released at $105^{\circ} \mathrm{C}$

$\mathrm{RMV}=$ Remaining moisture and volatiles after drying under given condition

ML = Moisture loss during drying

$\mathrm{RM}=$ Remain moisture after drying under given condition

$\mathrm{VL}=$ Volatile loss during drying

\section{Statistical analysis}

SAS computer software was used to fit the experimental data to a suitable model. These models were evaluated by using statistical parameters; Mean Relative Error (MRE),

$$
M R E=\frac{100}{N} \sum_{i=1}^{N}\left|\frac{M_{i, \exp -} M_{i, p r e}}{M_{i, \exp }}\right|
$$

Where $\mathrm{M}_{i}$ exp is the $\mathrm{i}^{\text {th }}$ experimental moisture content, $\mathrm{M}_{i}$, pre is the $\mathrm{i}^{\text {th }}$ predicted moisture content, $\mathrm{N}$ is number of observations. The means of the deviation of the different models were then compared using analysis of variance to determine whether the model predictions differed significantly from one another. The equation which gives a MRE / P value equal to or less than 5 is considered to be the good fit model.

The experimental data were compared with three sorption mathematical models; Modified Henderson, modified Chung-Pfost and GAB. The best fit model was evaluated using statistical parameters; correlation coefficient, Mean relative error, Standard error of estimates and randomness of residuals. The evaluation which gives the $\mathrm{P}$ value less than 5 can be considered as the best fitted model. To optimization of the dehydration process for selected crops, the data were analyzed using ANOVA and the means were separated according to the Duncan Multiple range Test.

\section{RESULTS AND DISCUSSION}

Three mathematical models used for ginger and nelli EMC data fitting. The results of model fitting at $30^{\circ} \mathrm{C}$ and $50^{\circ} \mathrm{C}$ are shown in Table 02 and 03. The data revealed that, modified chung- Pfost equation could be identified as best fitted in both adsorption and desertion temperature significantly $(P<5)$. Therefore this model is capable of producing the best results for the two temperature levels that could be used for the EMC estimation of Ginger and Nelli.

Remarkable variation cannot be identified between predicted and observed moisture contents. The sigmoid shape of curve could be identified at the range $0.2 \mathrm{a}_{\mathrm{w}}-0.8 \mathrm{a}_{\mathrm{w}}$ water activity levels belongs to type ii isotherm (Figure. 01 and Figure. 02) as explained by (Bell and Labuza , 2000). Thus the knowledge of moisture sorption isotherms, it is possible to predict the maximum moisture that the medicinal plant can be allowed to gain during storage (Cordeiro and Oliveira 2004).

A moisture sorption isotherm for ginger is presented in figures 03 and 04 , respectively at $30^{\circ} \mathrm{C}$ and $50^{\circ} \mathrm{C}$. The isotherms exhibited $\mathrm{S}$-shapes described as type II in the isotherms classification (Iglesias and Chirife, 1976). Type II isotherms are typical of foods high in carbohydrates (Bolin, 1980). Hence this shape of the isotherms was expected of ginger because of their high carbohydrate content of 60-70\%. The equilibrium moisture content of the samples increased as the water activity increased at constant temperature. Slopes of the isotherms were gentle at $\mathrm{a}_{\mathrm{w}}<0.55$ where relatively low moisture was absorbed for a high increase in $\mathrm{a}_{\mathrm{w}}$. 
Table 02: Model parameters for moisture adsorption and desorption of Ginger

\begin{tabular}{ccc}
\hline & \multicolumn{2}{c}{ Adsorption Temperature $\left({ }^{\circ} \mathrm{C}\right)$} \\
\cline { 2 - 3 } Model & $30{ }^{\circ} \mathrm{C}$ & $50^{\circ} \mathrm{C}$ \\
\hline Modified chung-Pfost & & \\
A & 151.71 & 484.77 \\
$\mathrm{~B}$ & 0.007 & 0.42 \\
$\mathrm{C}$ & -100.83 & 50.000 \\
\hline & \multicolumn{2}{c}{ Desorption Temperature $\left({ }^{\circ} \mathrm{C}\right)$} \\
\cline { 2 - 3 } & $30^{\circ} \mathrm{C}$ & $50^{\circ} \mathrm{C}$ \\
\hline Modified chung-Pfost & & \\
A & 122.13 & 223.77 \\
B & 0.06 & 0.05 \\
C & -103.14 & -78.23 \\
\hline
\end{tabular}

$\mathrm{A}, \mathrm{B}$ and $\mathrm{C}$ are the constants

Table 03: Model parameters for moisture adsorption and desorption of Nelli

\begin{tabular}{ccc}
\hline & \multicolumn{2}{c}{ Adsorption Temperature $\left({ }^{\circ} \mathrm{C}\right)$} \\
\cline { 2 - 3 } Model & $30^{\circ} \mathrm{C}$ & $50{ }^{\circ} \mathrm{C}$ \\
\hline Modified chung-Pfost & 0.0003 & 0.0004 \\
A & 0.238 & 0.599 \\
B & 58.950 & 62.705 \\
C & \multicolumn{2}{c}{} \\
\cline { 2 - 3 } & \multicolumn{2}{c}{ Desorption Temperature $\left({ }^{\circ} \mathrm{C}\right)$} \\
\hline Modified chung-Pfost & $30^{\circ} \mathrm{C}$ & $50^{\circ} \mathrm{C}$ \\
A & 344.50 & -0.0002 \\
B & -5.167 & -0.5182 \\
C & 58.0 & 265.384 \\
\hline
\end{tabular}

$\mathrm{A}, \mathrm{B}$ and $\mathrm{C}$ are the constants

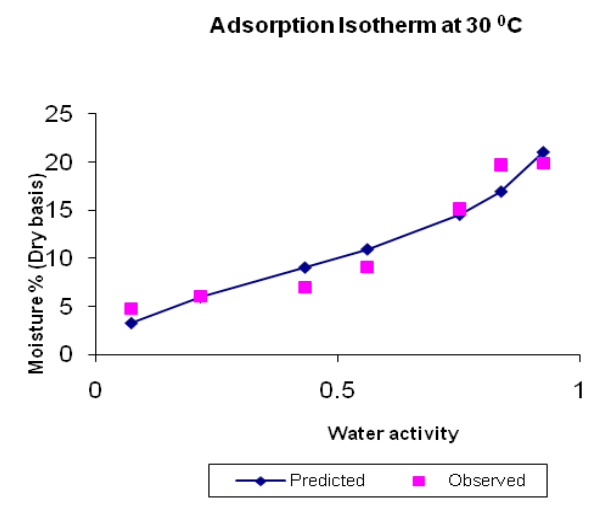

la

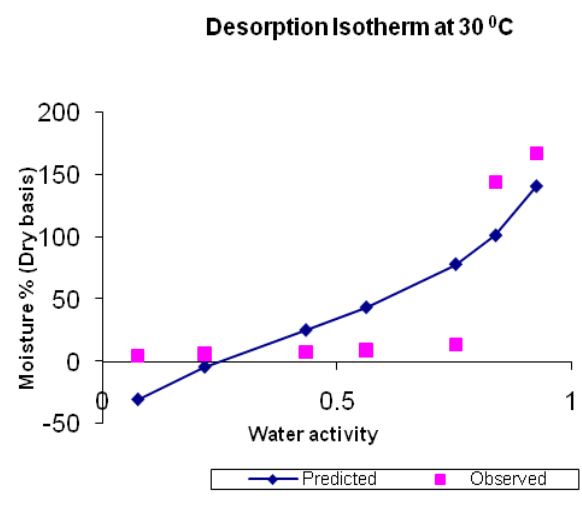

$1 \mathrm{~b}$

Figure 01: Best fitted model at $30{ }^{\circ} \mathrm{C}$ for Adsorption (1a) and desorption (1b) for Nelli 


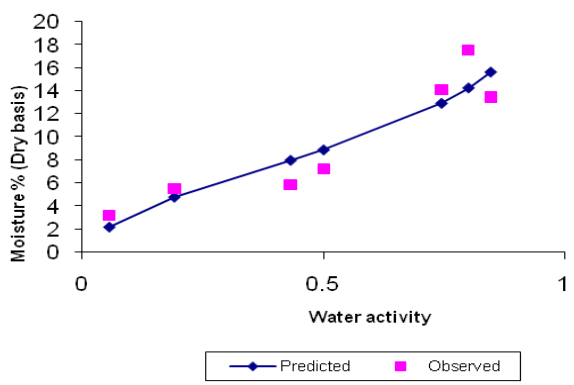

$2 \mathrm{a}$

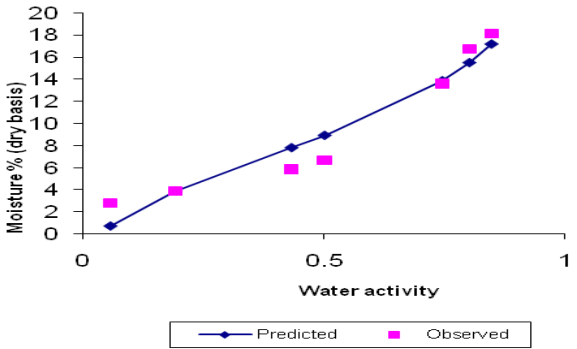

$2 b$

Figure 02: Best fitted model at $50^{\circ} \mathrm{C}$ for Adsorption (2a) and desorption (2b) for Nelli

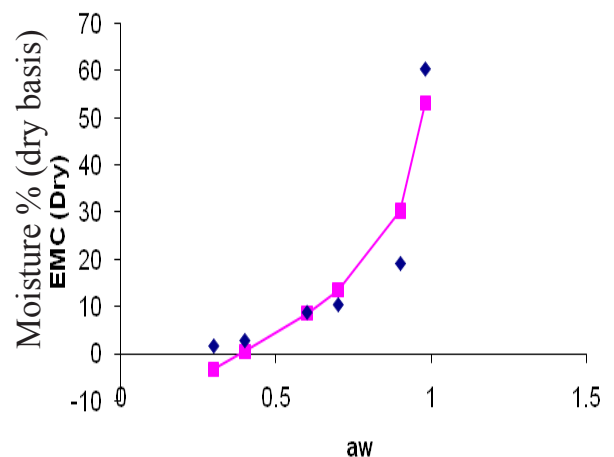

$3 \mathrm{a}$

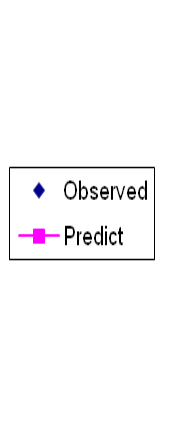

$3 b$

Figure 03: Best fitted model at $30^{\circ} \mathrm{C}$ for adsorption (3a) and desorption (3b) for Ginger

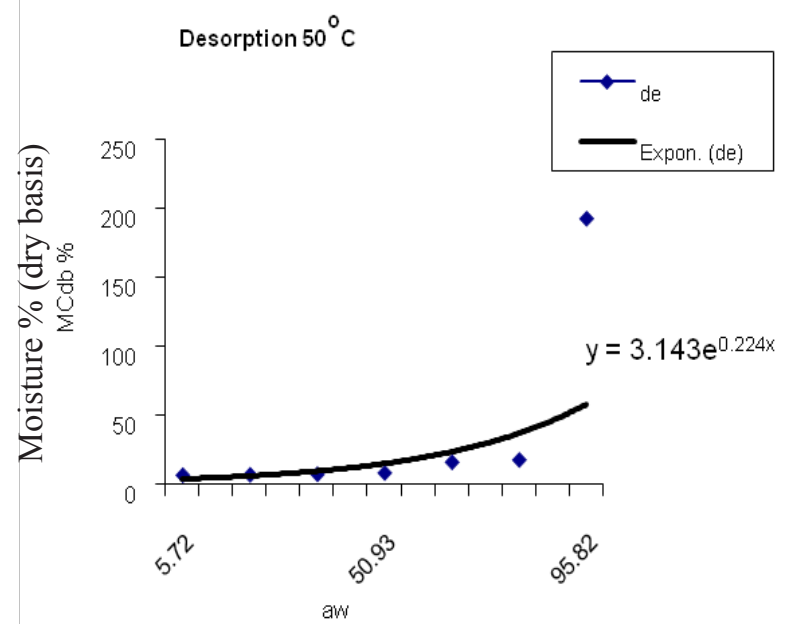

$4 \mathrm{a}$

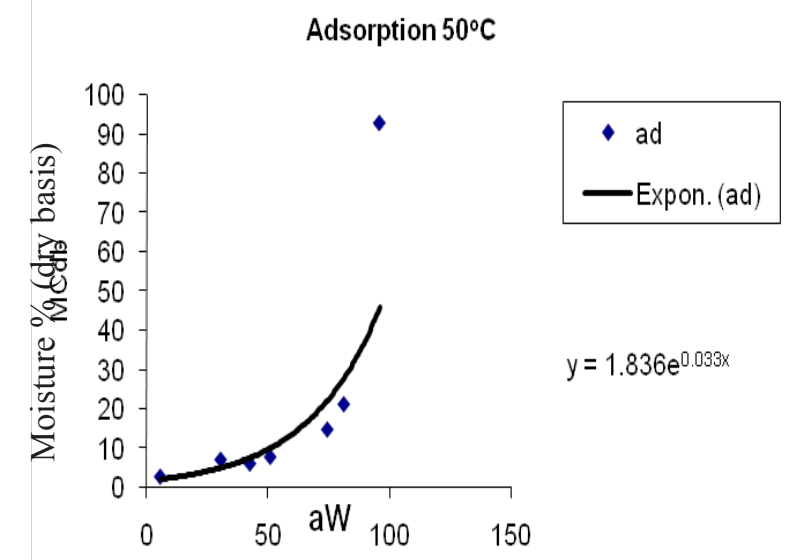

$4 b$

Figure 04: Best fitted model at $50^{\circ} \mathrm{C}$ for desorption (4a) and adsorption (4b) for Ginger Note: ${ }_{\mathrm{a}} \mathrm{w}$ - Water activity 
Table: 04. Optimum drying temperature for ginger and nelli

\begin{tabular}{ccccc}
\hline \multirow{2}{*}{ Crop } & \multirow{2}{*}{ Parameters } & \multicolumn{3}{c}{ Drying tempreture } \\
\cline { 3 - 5 } & & $40^{\circ} \mathrm{C}$ & $50^{\circ} \mathrm{C}$ & $60^{\circ} \mathrm{C}$ \\
\cline { 3 - 5 } Ginger & AS & $1.27^{\mathrm{a}}$ & $1.21^{\mathrm{ab}}$ & $1.19^{\mathrm{b}}$ \\
& WS & $13.36^{\mathrm{a}}$ & $12.89^{\mathrm{b}}$ & $12.53^{\mathrm{c}}$ \\
& M & $7.29^{\mathrm{a}}$ & $6.42^{\mathrm{b}}$ & $6.30^{\mathrm{c}}$ \\
\multirow{2}{*}{ Nelli } & AS & $1.70^{\mathrm{b}}$ & $2.03^{\mathrm{a}}$ & $1.64^{\mathrm{c}}$ \\
\cline { 2 - 4 } & WS & $9.63^{\mathrm{b}}$ & $9.75^{\mathrm{a}}$ & $9.45^{\mathrm{c}}$ \\
& M & $6.37^{\mathrm{b}}$ & $6.24^{\mathrm{a}}$ & $6.25^{\mathrm{c}}$ \\
\hline \multirow{2}{*}{ AS - Alcohol soluble extractives (\%), WS - Water soluble extractives (\%), M- Moisture content (\%) }
\end{tabular}

\section{Optimum drying temperature}

AS - Alcohol soluble extractives (\%), WS Water soluble extractives (\%), M- Moisture content $(\%)$

Note: Each value presents means of three replicates. Means in each raw followed by the same letter are not significantly different $(\mathrm{p}<0.05)$

$40^{\circ} \mathrm{C}$ is found to be the best suitable drying temperature for ginger by retaining high amount of Water soluble extractives (13.36\%), Alcohol soluble extractives (1.27\%), with low moisture content $7.29 \%$ where as Nelli giving the higher values of Water soluble extractives (9.75\%), Alcohol soluble extractives $(2.03 \%)$ and low moisture content $(6.37 \%)$ when drying at $50^{\circ} \mathrm{C}$ (Table 4). Because of having higher volatile constituents, the lower temperature $\left(40^{\circ} \mathrm{C}\right)$ may be efectively protect the final quality of the dehydrated Ginger.

\section{CONCLUSIONS}

Three drying models used in order to illustrate the drying behavior of Phylanthus ambelica (Nelli) and Zingiber officinale (Ginger) have been found that Modified Chung-Pfost model is best fitted with experimental data and most suitable for describing the relationship between equilibrium moisture content, the water activity and the temperature.

The suitable drying temperature for ginger and Nelli was identified as $40^{\circ} \mathrm{C}$ and $50^{\circ} \mathrm{C}$ respectively by retaining high amount of Water soluble extractives (\%), Alcohol soluble extractives $(\%)$, with low moisture content.

\section{References}

Abeywardana, N. Hettiaratchi, L.J.K. (2001). Statistics on the national demand for medicinal plants. Report No. MPP/R/21. IUCN Sri Lanka, Colombo.

Anon. (2013). Ginger (Zingiber officinale).Department of Export Agriculture. Sri Lanka

AOAC. (1990). Official methods of analysis. Vol 2, Association of Official Analytical Chemists, Inc., Verginia. pp 69-81.

Bell, N.L. and Labuza, T.P. (2000). Moisture Sorption: Practical aspects Isotherms Measurements $\&$ use American Association of Cereal Chemist, St. Paul, USA

Bolin, H. R. 1980. Retention of the water activity in prunes and raisin. Journal of Food Science, 45, 1190-1192. 
Copeland, L.O. and MacDonald, M.B. (1995).Seed science and technology.Chapman and Hall, New York,USA.

Cordeiro, D.S. and Oliveira, W.P. (2004). Drying of medicinal plants: Equilibrium moisture content and mathematical modeling of Maytenus ilicifolia leaves. Drying. Proceedings of the $14^{\text {th }}$ International Drying Symposium. Sao Paulo, Brazil, pp. 1712-1719.

Iglesias, H. A. and Chirife, J. (1976). On the local isotherm concept and mode of moisture bindings in food products. Journal of Agriculture and Food Chemistry, 24,77

Isuru J. and Gunawardena U.A. D. P. (2008). Utilization patterns of medicinal plants: A study in the Western Province of Sri Lanka. Proceedings of the 28th Annual Sessions of Institute of Biology, Sri Lanka.

Jayaweera, D.M.A. (1982). Medicinal plants (indigenous and exotic) used in Ceylon, Parts 1-5. National Science Council of Sri Lanka, Colombo.[

Palipane, K.B. and Discroll, R.H. (1992). Moisture sorption characteristics of in-shell macadamia nut. Journal of food Ingineering. 18:63-76.

Pushpakumara, D.K.N.G.,Gunasena, H.P.M. and Singh,V.P.(2007).Underutilized fruit trees in Sri Lanka. In. D.K.N.G Pushpakumara and H.M.S.Heenkenda (Eds), Nelli (AMLA). Sri Lanka Council for the Agricultural Research Policy., Asian Center for Underutilized Crops, Sri Lanka, pp 180-221.

Velthev, Z.N. and Menkow, N.D. (2000). Desorption isotherm of apple at several temperatures. Drying Technology. 18:1127-1137. 